\title{
Correlations among Social Anxiety, Self-Esteem, Impulsivity, and Game Genre in Patients with Problematic Online Game Playing
}

\author{
Jeong Ha Park ${ }^{1 *}$, Doug Hyun Han ${ }^{1 *}$, Bung-Nyun Kim², Jae Hoon Cheong ${ }^{3}$, and Young-Sik Lee ${ }^{1 凶}$ \\ ${ }^{1}$ Department of Psychiatry, Chung Ang University Hospital, Seoul, Republic of Korea \\ ${ }^{2}$ Department of Psychiatry, Seoul National University College of Medicine, Seoul, Republic of Korea \\ ${ }^{3}$ Uimyung Research Institute for Neuroscience, Samyook University, Seoul, Republic of Korea
}

\begin{abstract}
Objective Recent studies of online game addiction have suggested that social interaction and impulsivity are critical factors for the etiology and progress of online game addiction. We hypothesized that the genre of the online game is associated with impulsivity and sociality in individuals with online game addictions.

Methods In total, 212 patients with problematic online game playing were divided into four groups by game genre: 1) massive multiplayer online role playing game (MMORPG), 2) real-time strategy (RTS), 3) first-person shooter (FPS), and 4) other. Their symptoms and characteristics were assessed using 8 scales and 2 tests to estimate self-esteem, impulsiveness, comorbidity, social interaction status, and cognitive function.

Results The mean social anxiety score was highest in the MMORPG group and lowest in the FPS group. The mean self-esteem score was highest in the RTS group. Social anxiety score was positively correlated with Internet addiction score in the MMORPG group, and the selfesteem score was positively correlated with Internet addiction score in the RTS group.

Conclusion The genre of online game was not associated with impulsivity, but social anxiety status varied significantly with game genre, and differences in social anxiety were especially pronounced in patients playing the MMORPG (highest social anxiety) and FPS (lowest social anxiety) game genres. In addition, self-esteem was highest in the RTS game genre.

Psychiatry Investig 2016;13(3):297-304
\end{abstract}

Key Words Online game addiction, Online game genre, Social anxiety, Self-esteem, Impulsivity.

\section{INTRODUCTION}

Online game play represents a major portion of online entertainment activities whose excessive use has been viewed as a factor in many mental problems. ${ }^{1-4}$ In a review of 58 Internet addiction studies, Kuss and Griffiths ${ }^{5}$ suggested that the consequences of excessive online game playing include diminished academic performance, poor sleep, aggression, and personal problems managing relationships. ${ }^{6-9}$ Korea is one of the largest online gaming markets in the world, ${ }^{10}$ and online gaming there has created multiple social concerns regarding gaming addiction. Online game genre is one of several risk

Received: April 7, 2015 Revised: July 11, 2015

Accepted: July 27, 2015 Available online: January 8, 2016

$\triangle$ Correspondence: Young-Sik Lee, MD, PhD

Department of Psychiatry, Chung Ang University Hospital, 102 Heukseok-ro, Dongjak-gu, Seoul 06973, Republic of Korea

Tel: +82-2-6299-1508, Fax: +82-2-6299-1114, E-mail: hawkeyelys@hanmail.net

*These authors contributed to this work.

(a) This is an Open Access article distributed under the terms of the Creative Commons Attribution Non-Commercial License (http://creativecommons.org/licenses/bync/3.0) which permits unrestricted non-commercial use, distribution, and reproduction in any medium, provided the original work is properly cited. factors that might be related to the cause and progress of game addiction. ${ }^{11,12}$ We hypothesized that online game genre is associated with impulsivity and sociality in individuals with online game addiction.

\section{Online game genres}

Although there is a large variety of online games currently available, user mainly play one or two specific game genres. In discussing online games, the genre matters significantly; in this study, we used the " 2012 Korean Game Industry White Paper" $" 10$ online games classification, which is well-known and frequently referenced by online game players and publications world-wide. We used this classification to sort online game titles into three distinct genres and one aggregate "other" category of less commonly reported genres, as described below.

Role-playing games (RPGs) are rich in narrative and initially were usually designed to have a single player. Success depends on skills suited to achieving objectives in developing and managing characters. These games have evolved with the rapid expansion of Internet use into massive, multiplayer, online role- 
playing games (MMORPGs). In MMORPGs, players develop characters and interact collaboratively and competitively in a shared online world. MMORPGs enable simultaneous interaction among thousands of gamers. Thus, gameplay tends to emphasize socialization aspects. The never-ending and highly social nature of MMORPGs distinguishes them from other genres and might also increasing their addictive nature. ${ }^{13,14}$

Another popular genre of games, which differs markedly from MMORPGs, is first-person shooter (FPS). In this action subgenre, game players engage in combat with enemies, predominately using firearms. The shoot-to-kill style of FPS games is considered highly arousing and violent. ${ }^{15}$ To date, very little specific experimental research has investigated excessive FPS gaming. A recent survey has found that FPS gamers do report excessive gaming, with prevalence second only to that of MMORPGs. ${ }^{16}$

Real-time strategy (RTS) games are strategic combat-orientated games with no delay between moves. Other strategy games are turn-based (i.e., waiting on the player to act) and use other forms of strategic simulation. In RTS player matches, strategic decision-making ability directly influences the results and scores of game play. For example, in a battle of friendly forces versus enemy forces, a gamer might hold a combat commander position that makes use of multiple strategies to take over the enemy's fortress.

The remaining game genres include arcade games, online sports games, casual games, and other action games with uncomplicated playing rules; these are classified into the "others" category in this article.

\section{Personal characteristics and online game genres in the general population}

In Korea, several studies have linked personal characteristics and sociality to game genre among the general population of adolescents and adults. ${ }^{11,17,18}$ Agreeableness and extraversion appear to be strong motivation predictors for playing online games. However, personality traits do not seem to predict online gaming behavior in terms of overall game playing time or preference for specific genres of online games. Age has been positively associated with the escapism motivation for playing online games. ${ }^{17}$ Significant play pattern differences have been noted for the different game genres. Simulation, RPG, and shooting game users show a preference for playing with others. This preference is lower for web-based board game and sports game players than for other genre users. ${ }^{11}$

In past studies, high-risk Internet users seemed to have difficulty controlling their own behavior, which could be related to low self-confidence and emotional problems. ${ }^{19} \mathrm{To}$ extend this research, we analyzed in detail any specific differences in personal characteristics among the online game genres.
In particular, we examined the types of specific personal characteristics that could lead to overuse of online gaming in various genres compared to individuals in the general population who are frequently exposed to online games. Research on "who plays what and why" can provide a more complete picture of gamer personalities and motivations and improve the ability to assess the characteristics of patients with addiction to online gaming with respect to game genres.

Considering recent research regarding those in the general population who are frequently exposed to online games and from the perspective that social cognition is closely related to impulsivity and that these factors interact in predicting aggressive behavior ${ }^{20}$ we evaluated impulsivity and sociality with respect to social anxiety, self-esteem, and family environmental factors in patients with online gaming addiction.

\section{METHODS}

\section{Subjects}

We screened 352 patients with problematic online game play who visited the Online Game Clinic Center from June 2011 to June 2012. All patients were screened using the structured clinical interview of DSM-IV for psychiatric comorbidities, ${ }^{21,22}$ including assessment of history or current episode of Axis 1 psychiatric disorders. Exclusion criteria for the study included neurological or medical disorders. In addition, all participants were asked to complete questionnaires incorporating a measure of the severity of Internet addiction, the Family Environmental Scale, the Self-Esteem Scale, the Behavior Inhibition Scale (BIS)/Behavioral Activation System (BAS) Scale, the Social Avoidance Scale, Dupaul's Attention-Deficit/ Hyperactivity Disorder Rating Scale, Beck Depression Inventory, Beck Anxiety Inventory, an IQ test, and the Wisconsin Card Sorting Test.

The criteria for online game addiction in the current study are similar to those applied in previous studies; all of the following criteria must be met for a diagnosis of online game addition: $:^{23,24} 1$ ) duration of online game play longer than 4 hours per day or 30 hours per week, 2) Young Internet Addiction Scale (YIAS) score greater than 50, ${ }^{25} 3$ ) irritable, anxious, and aggressive behaviors when forced to stop online game play, 4) impaired behaviors or distress, economic problems, and maladaptive patterns in regular life due to excessive online game play, and 5) irregular life pattern due to disrupted diurnal rhythms (sleeping during the day and gaming at night, irregular meals, and failure to maintain personal hygiene), school truancy, or loss of job. Of the 352 initially identified patients, 212 met all the criteria and were included in this study.

The research protocol for the current study was approved by the Chung Ang University Hospital Institutional Review 
Board. Written informed consent was received from patients at least 18 years of age. For adolescents younger than 18 years, written informed consent was provided by both the parents and the adolescents.

\section{Estimated scales}

\section{Self-esteem}

The Self-Esteem Scale-Korean (SES-K) is a two-factor selfesteem assessment modified from the Rosenberg Self-Esteem Scale, ${ }^{26}$ which consists of 10 statements regarding global feelings toward the self. For each item, participants are asked to indicate their level of agreement on a four-point Likert scale ( $1=$ completely disagree, $4=$ agree completely). Rosenberg described self-esteem as an individual's sense of worthiness that combines self-respect and self-confidence. The SES-K consists of 12 statements divided into 6 individual factor statements and 6 group factor statements; it was verified by Han and Jeong. The internal consistency of the SES-K is good, with a Cronbach's $\alpha$ of 0.79 . The total mean score (SD) of the s individual and group elf-esteem factors were 16.77 (2.44) and 18.43 (2.08), respectively. ${ }^{27}$

\section{Impulsiveness}

The Behavioral Inhibitory System (BIS)/Behavioral Activation System (BAS) Scale is a self-report measure of impulsiveness. ${ }^{28}$ Carver and White ${ }^{28}$ created the BIS/BAS scale to estimate stable individual differences in BIS and BAS sensitivities. Specifically, the BAS comprises reward responsiveness (RR), drive, and fun seeking (FS). The Korean version of the BIS/ BAS was verified by Kim and Kim. ${ }^{29}$ The BIS/BAS uses a four-point Likert scale ranging from $1=$ not at all to $4=$ strongly agree, and its total score ranges from 0 to 80 points. The BIS/ BAS's internal consistency (Cronbach's $\alpha$ ) has been reported to range from 0.78 to $0.79 .{ }^{29}$ More specifically, the alpha value of the BIS has been reported as 0.78 , that of the BAS-RR as 0.85 , that of the BAS-drive as 0.87 , and that of the BAS-FS as 0.78 .

\section{Comorbidity}

The Beck Depression Inventory (BDI) is a widely used depression symptom severity scale composed of 21 items..$^{30}$ Each question is scored on a scale of 0 to 3 , so the total score of the $\mathrm{BDI}$ ranges from 0 to 63 points. The BDI was created by Beck in 1961 and was revised in 1978. The Korean version of the BDI was verified by Rhee et al. ${ }^{31}$ Internal consistency of the $\mathrm{BDI}$ has been reported to range from 0.75 to 0.85 .

The Beck Anxiety Scale (BAI) is a widely used anxiety symptom severity scale composed of 21 items. ${ }^{32}$ The BAI is an inventory created by Beck in 1988 to measure clinical anxiety while minimizing the overlap between depression and anxiety scales. The BAI items are each scored on a scale of 0 to 3 , and its maximum score is 63 points. The Korean version of the BAI was verified by Kwon et al. ${ }^{33}$ The internal consistency of the BAI-Korean version is good, with a Cronbach's $\alpha$ of 0.93 .

Dupaul's Attention-Deficit/Hyperactivity Disorder (ADHD) Rating Scale-Korean Version (K-ARS) is an ADHD symptom severity scale composed of 18 items (9 items assessing inattention and 9 items assessing hyperactivity) designed by Dupaul. ${ }^{34}$ The Korean version of the ARS was verified by So et al. ${ }^{35}$ Internal consistency of the K-ARS has been reported to be good, with Cronbach's alpha ranging from 0.77 to 0.89 .

\section{Social interaction status}

The Family Environmental Scale (FES) was created to estimate the social-environmental characteristics of a family; it has 90 items in 3 subdomains (relationship, personal growth, and system maintenance). ${ }^{36}$ Its relationship domain, consisting of conflict, expressiveness, and family cohesion subscales, assesses the family relationship. ${ }^{36}$ The Korean version of the FES was verified by Park et al. ${ }^{37}$ it has 72 items forming 9 subscales. The internal consistency (Cronbach's $\alpha$ ) of each subscale has ranged from 0.45 to 0.77 , and the test-retest reliability of the Korean version of the scale has ranged from 0.68 to 0.86 .

The Social Avoidance and Distress Scale (SADS) assesses the severity of social anxiety and avoidance tendency via 28 questions. The SADS uses true-false responses, so its total score ranges from 0 to 28 points. ${ }^{38}$ Higher scores indicate greater anxiety and avoidance tendency. The test-retest reliability of the SADS-Korean version was shown to be $0.68 .{ }^{39}$

\section{Cognitive function}

The Korean-Wechsler Adult Intelligent Scale (K-WAIS) was used in this study to assess the intelligence quotient (IQ) of the participants. ${ }^{40}$ Internal consistency of the K-WAIS has been reported to be high, with Cronbach's alpha ranging from 0.78 to 0.94 .

We used a computerized version of the Wisconsin Card Sorting Test to assess executive function, including set shifting, working memory, and inhibitory control processing (CNT4.0, Maxmedica Inc.). ${ }^{41}$ The reliability of the test was reported as Cronbach's $\alpha=0.783 .{ }^{41}$ The WCST sub-item for perseverative error, which represents set shifting, is thought to be associated with prefrontal cortex function. ${ }^{42}$

\section{Data analysis}

Demographic characteristics and assessment scales scores for all patients were analyzed using one-way ANOVA. Controlling for age, FES, and SES-K, the partial correlation between SADS and severity of Internet addiction was analyzed in the MMORPG group. Controlling for age, FES, and SADS, 
the partial correlation between SES-K and severity of Internet addiction was analyzed in the RTS group.

\section{RESULTS}

\section{Demographic characteristics}

Of the 212 patients, 83 were preoccupied with MMORPGs (39.2\%), 74 with RTSs (34.9\%), 34 with FPSs (16.0\%), and 21 with games in other genres (9.9\%). The online game addiction composition of the 212 patients included 79 with online game addiction alone; the others had additional problems: 64 with ADHD, 40 with major depression, 11 with dual diagnosis of ADHD and major depression, 6 with schizophrenia, 3 with obsessive compulsive disorder, 2 with alcohol dependence, 4 with autism spectrum disorders, and 3 with mental retardation. There were no significant differences in age, YIAS score, online game-playing time, K-ARS scores, BAI-K scores, or IQ among the four groups. However, the YIAS-parent scores in the MMORPG group were higher than those in the other three groups $(\mathrm{F}=6.2, \mathrm{p}<0.01)$. The BDI-K scores in the "others" group were higher than that in the RTS group $(\mathrm{F}=3.4$, $\mathrm{p}=0.02$ ) (Table 1). There were no significant differences in psychiatric comorbidity among the 4 groups (Table 1).

\section{Social factors}

There were significant group differences with regard to social anxiety $(\mathrm{F}=8.5, \mathrm{p}<0.01)$ and self-esteem $(\mathrm{F}=4.8, \mathrm{p}<0.01)$. In post-hoc testing, the mean Social Anxiety Scale score was higher in the MMORPG group than in the other three groups. The mean social anxiety score was lower in the FPS group than in the other three groups. Both subscales of the social anxiety scale, social avoidance $(\mathrm{F}=8.2, \mathrm{p}<0.01)$ and social anxiety $(\mathrm{F}=6.8, \mathrm{p}<0.01)$, had higher mean scores in the MMORPG group than in the other three groups. Self-esteem scores in the RTS group were higher than those in the other three groups. Scores on a subscale of self-esteem, SES-group, were higher in the RTS group than in the other three groups $(\mathrm{F}=7.2$, $\mathrm{p}<0.01)$. However, there was no significant difference in sub-

Table 1. Demographic characteristics

\begin{tabular}{|c|c|c|c|c|c|}
\hline & MMORPG $(\mathrm{N}=83)$ & RTS $(\mathrm{N}=74)$ & FPS $(\mathrm{N}=34)$ & Others $(\mathrm{N}=21)$ & Statistics \\
\hline Sex (male/female) & $81 / 2$ & $74 / 0$ & $32 / 2$ & $20 / 1$ & $\chi^{2}=4.1, p=0.25$ \\
\hline Age (years) & $21.2 \pm 6.2$ & $20.7 \pm 4.7$ & $18.9 \pm 5.9$ & $21.4 \pm 6.9$ & $\mathrm{~F}=1.41, \mathrm{p}=0.24$ \\
\hline School years & $10.8 \pm 2.5$ & $11.6 \pm 2.2$ & $10.8 \pm 2.7$ & $12.2 \pm 1.7$ & $\mathrm{~F}=0.79, \mathrm{p}=0.51$ \\
\hline YIAS & $64.1 \pm 11.4$ & $62.7 \pm 10.8$ & $61.6 \pm 11.8$ & $64.6 \pm 13.0$ & $\mathrm{~F}=1.84, \mathrm{p}=0.14$ \\
\hline YIAS-parent & $67.8 \pm 10.8$ & $62.7 \pm 10.8$ & $62.1 \pm 6.2$ & $62.9 \pm 5.1$ & $\begin{array}{c}\mathrm{F}=4.22, \mathrm{p}=0.01 \\
\mathrm{M}>\mathrm{R}, \mathrm{F}, \mathrm{O}^{*}\end{array}$ \\
\hline GP time & $6.4 \pm 2.5$ & $6.4 \pm 2.7$ & $6.3 \pm 2.8$ & $5.6 \pm 2.5$ & $\mathrm{~F}=0.53, \mathrm{p}=0.66$ \\
\hline K-ARS & $16.1 \pm 10.7$ & $13.3 \pm 8.3$ & $14.8 \pm 7.8$ & $15.7 \pm 10.7$ & $\mathrm{~F}=1.77, \mathrm{p}=0.15$ \\
\hline BDI-K & $13.5 \pm 7.8$ & $12.5 \pm 6.4$ & $12.1 \pm 6.3$ & $18.1 \pm 9.0$ & $\begin{array}{c}\mathrm{F}=4.39, \mathrm{p}=0.01 \\
\mathrm{M}, \mathrm{R}, \mathrm{F}<\mathrm{O}^{*}\end{array}$ \\
\hline BAI-K & $8.5 \pm 6.6$ & $7.8 \pm 5.9$ & $8.3 \pm 6.3$ & $9.4 \pm 6.0$ & $\mathrm{~F}=0.43, \mathrm{p}=0.73$ \\
\hline IQ & $104.9 \pm 14.4$ & $105.5 \pm 14.7$ & $99.4 \pm 12.8$ & $103.6 \pm 14.7$ & $\mathrm{~F}=2.11, \mathrm{p}=0.10$ \\
\hline \multicolumn{6}{|l|}{ Comorbidity } \\
\hline OGA-no comorbidity & 23 & 33 & 15 & 8 & $\chi^{2}=2.63, p=0.45$ \\
\hline Co-ADHD & 30 & 18 & 10 & 6 & $\chi^{2}=1.41, \mathrm{p}=0.70$ \\
\hline Co-MDD & 18 & 12 & 5 & 5 & $\chi^{2}=1.02, p=0.80$ \\
\hline Co-ADHD+MDD & 4 & 4 & 3 & 2 & $\chi^{2}=1.02, p=0.80$ \\
\hline $\mathrm{Co}-\mathrm{Sz}$ & 3 & 1 & 0 & 0 & $\chi^{2}=2.42, p=0.49$ \\
\hline Co-OCD & 1 & 2 & 0 & 0 & $\chi^{2}=1.65, p=0.65$ \\
\hline Co-alcohol & 1 & 1 & 0 & 0 & $\chi^{2}=0.71, p=0.87$ \\
\hline Co-ASD & 2 & 2 & 0 & 0 & $\chi^{2}=1.41, p=0.70$ \\
\hline Co-MR & 1 & 1 & 1 & 0 & $\chi^{2}=0.87, p=0.83$ \\
\hline
\end{tabular}

*post hoc p<0.05. OGA-no comorbidity: online game addiction without psychiatric comorbidities, MMORPG: massive multiplayer online role playing game, RTS: real-time strategy, FPS: first-person shooter, YIAS: Young Internet Assessment Scale, GP time: game playing time, KARS: Dupaul's ADHD Scale-Korean version, BDI-K: Beck Depression Inventory-Korean version, BAI-K: Beck Anxiety Scale-Korean version, IQ: intelligence quotient, Co-ADHD: comorbid with attention deficit hyperactivity disorder, MDD: major depressive disorder, Sz: schizophrenia, OCD: obsessive compulsive disorder, Alcohol: alcohol dependence, ASD: autism spectrum disorder, MR: mental retardation, M: MMORPG, R: RTS, F: FPS, O: others 
scale scores for SES-individual (Table 2).

\section{Correlations among YIAS-K scores, SADS scores, and SES scores}

After controlling for age, FES score, and SES-K score, social anxiety was positively correlated with the YIAS score in the MMORPG group $(\mathrm{r}=0.428, \mathrm{p}<0.01)$. After controlling for age, FES score, and SADS score, self-esteem was positively correlated with YIAS score in the RTS group $(\mathrm{r}=0.39, \mathrm{p}<0.01)$ (Figure 1).

\section{DISCUSSION}

Our results indicate that sociality and self-esteem are personal factors of problematic online gaming that are related to game genre, suggesting that they are predictive factors of the core problems in specific online game genres.

\section{MMORPG}

Many studies, including several of the general population in Korea, have suggested that the MMORPG genre is strong-

Table 2. Comparisons of social factors and impulsivity among the four groups

\begin{tabular}{|c|c|c|c|c|c|}
\hline & MMORPG $(\mathrm{N}=83)$ & RTS $(\mathrm{N}=74)$ & FPS $(\mathrm{N}=34)$ & Others $(\mathrm{N}=21)$ & Statistics \\
\hline FES & $2.9 \pm 1.5$ & $3.3 \pm 1.8$ & $3.3 \pm 1.6$ & $3.2 \pm 1.7$ & $\mathrm{~F}=0.19, \mathrm{p}=0.91$ \\
\hline BIS/BAS & $53.4 \pm 9.0$ & $52.9 \pm 8.4$ & $53.1 \pm 8.4$ & $54.2 \pm 6.8$ & $\mathrm{~F}=0.16, \mathrm{p}=0.92$ \\
\hline SADS & $84.8 \pm 15.9$ & $77.5 \pm 12.8$ & $70.4 \pm 18.2$ & $77.8 \pm 8.9$ & $\begin{array}{c}\mathrm{F}=8.52, \mathrm{p}<0.01 \\
\mathrm{M}>\mathrm{R}, \mathrm{O}>\mathrm{F}^{*}\end{array}$ \\
\hline SADS-avoid & $41.2 \pm 8.7$ & $37.5 \pm 6.9$ & $33.8 \pm 9.2$ & $36.4 \pm 5.1$ & $\begin{array}{c}\mathrm{F}=8.19, \mathrm{p}<0.01 \\
\mathrm{M}>\mathrm{R}, \mathrm{F}, \mathrm{O}^{*}\end{array}$ \\
\hline SADS-anx & $43.5 \pm 8.3$ & $40.0 \pm 6.8$ & $36.8 \pm 8.8$ & $40.9 \pm 5.2$ & $\begin{array}{c}\mathrm{F}=6.79, \mathrm{p}<0.01 \\
\mathrm{M}>\mathrm{R}, \mathrm{F}, \mathrm{O}^{*}\end{array}$ \\
\hline SES & $29.2 \pm 8.6$ & $34.8 \pm 8.3$ & $29.8 \pm 6.1$ & $28.9 \pm 6.6$ & $\begin{array}{c}\mathrm{F}=4.87, \mathrm{p}<0.01 \\
\mathrm{R}>\mathrm{M}, \mathrm{R}, \mathrm{O}^{*}\end{array}$ \\
\hline SES-indv & $16.5 \pm 5.3$ & $17.6 \pm 5.1$ & $16.0 \pm 3.7$ & $15.3 \pm 3.8$ & $\mathrm{~F}=2.65, \mathrm{p}=0.08$ \\
\hline SES-group & $13.7 \pm 4.8$ & $16.2 \pm 4.2$ & $13.2 \pm 2.4$ & $13.3 \pm 3.6$ & $\begin{array}{c}\mathrm{F}=3.83, \mathrm{p}=0.01 \\
\mathrm{R}>\mathrm{M}, \mathrm{R}, \mathrm{O}^{*}\end{array}$ \\
\hline
\end{tabular}

*post hoc p<0.05. MMORPG: massive multiplayer online role playing game, RTS: real-time strategy, FPS: first person shooter, FES: Family Environmental Scale, BIS/BAS: Behavioral Inhibitory System/Behavioral Activation System Scale, SADS: Social Avoidance and Distress Scale, SADS-avoid: Social Avoidance and Distress Scale-Avoidance, SADS-anx: Social Avoidance and Distress Scale-Social Anxiety, SES: Self-Esteem Scale, SES-indv: Self-Esteem Scale-Individual, M: MMORPG, R: RTS, F: FPS, O: others
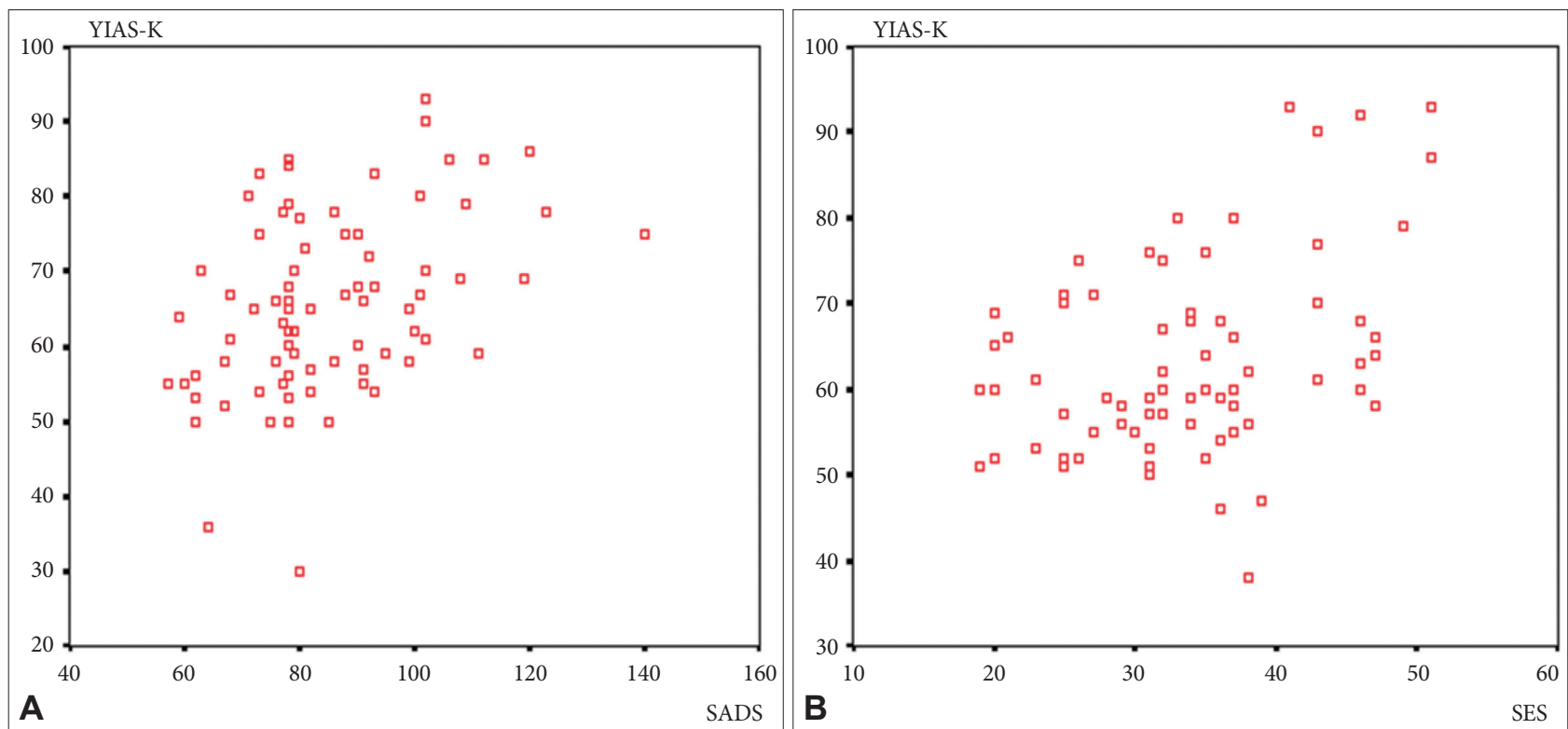

Figure 1. Correlation of YIAS-K score with SADS score and of YIAS-K score with Self-Esteem (SES) score. A: Partial correlation between Social Anxiety Scale score and YIAS score in the MMORPG group $(r=0.428, p<0.01)$. B: Partial correlation between SES Scale score and YIAS score in the RTS group ( $r=0.39, p<0.01)$. YIAS-K: Young Internet Addiction-Korean, RTS: real-time strategy. 
ly associated with a high degree of problematic online game play. ${ }^{11,16,43-46}$ Similarly, the MMORPG group in the current research had a higher degree of Internet addiction, as measured by the YIAS score reported by parents, than the other game genre groups. This finding suggests that the MMORPG genre is particularly likely to lead to gaming addiction in general online game players as well as in problematic online gamers, and that MMORPG gamers seem to be more highly addicted than gamers in other genres. This phenomenon might be partially explained by the characteristics of MMORPGs, such as the endless series of games and their variable reinforcement schedules that encourage continued game play, similar to gambling. ${ }^{47}$

Upon detailed examination of the results, the MMORPG group showed higher social anxiety and avoidance than the other groups. In previous studies, players who played MMORPGs to escape from reality experienced more problems as a consequence of gaming than those playing MMORGs for other reasons. ${ }^{48,49}$ Extending these findings, our research suggests that individual social functioning is a crucial factor influencing the desire to escape from reality and achieve relief and reduced anxiety or concerns. High personal social anxiety and high social avoidance tend to make people anxious and distressed when facing various social concerns, such as academic problems, problems in relationships with friends, and worries about the future. A cyber reality space like that found in MMOPRG games might allow players to feel they are escaping from their real social problems. Because escapism is a strong predictor of problematic gaming behavior, ${ }^{49}$ social anxiety and avoidance are typical personal characteristics of problematic online gamers, especially in players of MMORPGs. Our finding is consistent with a randomized experiment that showed MMORPGs impact the development of social and emotional skills of the players. ${ }^{6}$ From this result, we can cautiously deduce that MMORPGs might also aggravate players' poor social skills, creating a vicious cycle. Therefore, the clearest theme that emerges from the present study is that, when approaching a problematic MMORPG gamer, we should assess the player's social factors and tendencies in order to predict the progress of addictive behaviors and determine the future prognosis and therapeutic goals that might improve the player's social ability in the real world.

\section{FPS}

On the other end of the spectrum, social anxiety was lowest in the FPS group compared to the other three groups. An earlier study showed that most online FPS players do not play in isolation, and a social interaction motive was the strongest predictor of the duration of time spent on FPS play. ${ }^{50}$ Additionally, FPS players tend to be more competitive, seek chal- lenges, and get excited by doing so. ${ }^{50}$ Since FPS players control the game character from a first-person view, their selfconfidence is crucial for high scores and game amusement in this competition. Additionally, the highly immersive nature of FPS games, as well as their potential for online competition, achievements, and social aspects might contribute to high rates of excessive FPS gaming. Social-seeking behavior is inversely related to social anxiety and avoidance, which suggests that the low social anxiety of FPS players compared to that of those in the other three groups reflects their personal characteristics and motivation.

\section{RTS}

Self-esteem was higher in the RTS group than in the other three groups. This suggests that the strategic simulation information tasks of RTS games are more enjoyable when the gamer's self-esteem is stronger. Moreover, an RTS game involves many challenging tasks involving rapid switching, multiple sources of information, and multiple actions, which might lead to substantial cognitive flexibility. ${ }^{51}$ To be successful, a player must cope with simultaneous and rapidly evolving game situations and sub-situations occurring in real-time while also managing funds, resources, and information regarding the opponent. Self-esteem can have a decisive effect on judgment and decision making in managing multiple, simultaneous game strategies, reducing gamer anxiety and enhancing performance. Additionally, the lower social anxiety and social avoidance scores of RTS players compared to MMORPG players might be associated with the higher self-esteem found in these users. Thus, relatively high self-esteem and low social anxiety and avoidance seem to be the main individual characteristics in the RTS group.

\section{Others}

In the last group in this study, those who mainly play arcades games, sports online games, and casual games, gamers tended to be more depressed than in the other three groups. They had BDI test scores ranging from 16 to 23 , indicative of moderate depression. In contrast, the other three groups' BDI scores showed mild depression levels. The games in the "others" group have relatively simple designs with easy general game rules compared to other game genres; thus, these gamers' motivations and attitudes in choosing these games might include a desire for less challenging games. It is likely that people who have less volition or energy or some sort of difficulty concentrating, possibly due to depressed mood, could approach this genre of games more readily than other, more complex game genres.

The limitations of this study and suggestions for future research are addressed here. First, because this study is correla- 
tional and cross-sectional, the order of causality is not determined. Thus, it remains unclear whether the personal characteristics of the individuals in each game genre contributed to their genre selection and subsequent addiction or whether being preoccupied with a specific game genre creates or reinforces such characteristics. Second, the sample we used was self-selected, so its ability to represent problematic online game users in each game genre and to generalize our results to the general population might be limited. Third, due to the absence of a comparison group to represent the healthy population, questions remain about the meaningful differences between problematic online game users and healthy subjects.

Future research that includes prospective methods, such as follow-up, would add to the current study's findings. Moreover, observing gamer sociality, self-esteem, and other personal characteristics could aid understanding of causality between personal characteristics and gaming problems including gaming addiction. Additionally, it would be interesting to study whether individuals with changes in brain pathophysiology according to addiction level and treatment outcome have associated changes in sociality, self-esteem, and other features.

When evaluating and providing treatment to problematic online gamers, we can assess gamers' specific characteristics and psychopathological problems to look for a healthy balance. Assessing the treatment response regarding addictive behavior for online games might be represented by measuring the degree of improvement in defective characteristics within each game genre. Finally, the role of personality in game genre preference remains an important open question for ongoing research. Although the addictive personality hypothesis has largely fallen from scientific favor, game genre might ultimately mediate the causal relationships between personal characteristics, such as sensation seeking or impulsivity, and problematic video game play.

\section{Conclusions}

In this study, we found that sociality, represented by social anxiety, self-esteem, and familial environment, was correlated with game genre preference. However, impulsivity was not correlated with game genre. Moreover, individuals' specific characteristics, such as social anxiety, appeared to be strongly associated with gaming-related problems, similar to addictive issues in the MMORPG group, and self-esteem was intimately related to addictive behavior in the RTS group.

\section{Acknowledgments}

This study was supported by a grant of the Korean Mental Health Technology R\&D Project, Ministry of Health \& Welfare, Republic of Korea (HM14C2238). We also give special thanks to the Game Culture Foundation.

\section{REFERENCES}

1. Block JJ. Issues for DSM-V: internet addiction. Am J Psychiatry 2008; 165:306-307.

2. Christakis DA, Moreno MM, Jelenchick L, Myaing MT, Zhou C. Problematic internet usage in US college students: a pilot study. BMC Med 2011;9:77.

3. Pies R. Should DSM-V designate "Internet Addiction" a mental disorder? Psychiatry (Edgmont) 2009;6:31-37.

4. Siomos KE, Dafouli ED, Braimiotis DA, Mouzas OD, Angelopoulos NV. Internet addiction among Greek adolescent students. Cyberpsychol Behav 2008;11:653-657.

5. Kuss DJ, Griffiths MD. Internet and gaming addiction: a systematic literature review of neuroimaging studies. Brain Sci 2012;2:347-374.

6. Smyth JM. Beyond self-selection in video game play: an experimental examination of the consequences of massively multiplayer online roleplaying game play. Cyberpsychol Behav 2007;10:717-721.

7. Dworak M, Schierl T, Bruns T, Struder HK. Impact of singular excessive computer game and television exposure on sleep patterns and memory performance of school-aged children. Pediatrics 2007;120:978-985.

8. Sublette VA, Mullan B. Consequences of play: a systematic review of the effects of online gaming. Int J Ment Health Ad 2012;10:3-23.

9. Liu M, Peng W. Cognitive and psychological predictors of the negative outcomes associated with playing MMOGs. Comput Human Behav 2009;25:1306-1311.

10. Agency KCC. Korean Game Industry White Paper. Seoul: Korea Creative Content Agency; 2012.

11. Lee MS, Ko YH, Song HS, Kwon KH, Lee HS, Nam M, et al. Characteristics of Internet use in relation to game genre in Korean adolescents. Cyberpsychol Behav 2007;10:278-285.

12. Kim JW, Han DH, Park DB, Min KJ, Na C, Won SK, et al. The relationships between online game player biogenetic traits, playing time, and the genre of the game being played. Psychiatry Investig 2010;7:17-23.

13. Griffiths MD, Davies MN, Chappell D. Online computer gaming: a comparison of adolescent and adult gamers. J Adolesc 2004;27:87-96.

14. Ghuman D, Griffiths MD. A cross-genre study of online gaming: player demographics, motivation for play, and social interactions among players. Int J Cyber Behav Psychol Learn 2012;2:13-29.

15. Metcalf O, Pammer K. Impulsivity and related neuropsychological features in regular and addictive first person shooter gaming. Cyberpsychol Behav Soc Netw 2014;17:147-152.

16. Elliott L, Golub A, Ream G, Dunlap E. Video game genre as a predictor of problem use. Cyberpsychol Behav Soc Netw 2012;15:155-161.

17. Park J, Song Y, Teng CI. Exploring the links between personality traits and motivations to play online games. Cyberpsychol Behav Soc Netw 2011;14:747-751.

18. Jeong EJ, Kim DH. Social activities, self-efficacy, game attitudes, and game addiction. Cyberpsychol Behav Soc Netw 2011;14:213-221.

19. Chak K, Leung L. Shyness and locus of control as predictors of internet addiction and internet use. Cyberpsychol Behav 2004;7:559-570.

20. Fite JE, Goodnight JA, Bates JE, Dodge KA, Pettit GS. Adolescent aggression and social cognition in the context of personality: impulsivity as a moderator of predictions from social information processing. Aggress Behav 2008;34:511-520.

21. Ha JH, Yoo HJ, Cho IH, Chin B, Shin D, Kim JH. Psychiatric comorbidity assessed in Korean children and adolescents who screen positive for Internet addiction. J Clin Psychiatry 2006;67:821-826.

22. Kusumakar V, MacMaster FP, Gates L, Sparkes SJ, Khan SC. Left medial temporal cytosolic choline in early onset depression. Can J Psychiatry 2001;46:959-964.

23. Han DH, Hwang JW, Renshaw PF. Bupropion sustained release treatment decreases craving for video games and cue-induced brain activity in patients with Internet video game addiction. Exp Clin Psychopharmacol. 2010;18:297-304.

24. Ko CH, Liu GC, Hsiao S, Yen JY, Yang MJ, Lin WC, et al. Brain activi- 
ties associated with gaming urge of online gaming addiction. J Psychiatr Res 2009;43:739-747.

25. Young KS. Psychology of computer use: XL. Addictive use of the internet: a case that breaks the stereotype. Psychol Rep 1996;79:899-902.

26. Rosenberg M. Society and the Adolescent Self-Image. Princeton, NJ: Princeton University Press; 1965.

27. Han YH, Chung JK. Two-factor self-esteem scale: individualistic and collectivistic factors. Korean J Psychol 2007;21:117-131.

28. Carver CS, White TL. Behavioral inhibition, behavioral activation, and affective responses to impending reward and punishment: The BIS/ BAS scales. J Pers Soc Psychol 1994;67:319-333.

29. Kim KH, Kim WS. Korean-BAS/BIS scale. Korean J Health Psychol 2001;6:19-37.

30. Beck AT, Ward CH, Mendelson M, Mock J, Erbaugh J. An inventory for measuring depression. Arch Gen Psychiatry 1961;4:561-571.

31. Rhee MK, Lee YH, Park SH, Sohn CH, Chung YC, Hong SK, et al. A standardization study of Beck depression inventory I - Korean Version (K-BDI): reliability and factor analysis. Korean J Psychopathol 1995; 4:77-95.

32. Beck AT, Epstein N, Brown G, Steer RA. An inventory for measuring clinical anxiety: psychometric properties. J Consult Clin Psychol 1988;56:893-897.

33. Kwon SM. Assessment of psychopathology in patient with anxiety disorder. Korean J Psychopathol 1997;6:37-51.

34. Dupaul GJ. Parent and teacher ratings of ADHD symptoms - psychometries in a community based sample. J Clin Child Psychol 1991;20:245253.

35. So YK, Noh JS, Kim YS, Ko SG, Koh YJ. The reliability and validity of Korean parent and teacher ADHD rating scale. J Korean Nueropsychiatr Assoc 2002;41:283-289.

36. Moos R, Mood B. Family Environment Scale Manual. Palo Alto, CA: Mind Garden; 2002.

37. Park JH. Validity of the family environment scale-Korean version. J Korean Fam Ther 2004;12:1-26.

38. Watson D, Friend R. Measurement of social-evaluative anxiety. J Consult Clin Psychol 1969;33:448-457.
39. Lee JY, Choi JH. The effects of the cognitive-behavioral and exposure therapy for social phobia. Korean J Counsel Psychother 1997;9:35-56.

40. Kim JK, Yum TH, Oh KJ, Park YS, Lee YH. Factor analysis of K-WAIS revised version. Korean J Clin Psychol 1992;11:1-10.

41. Lee JA, Shin DJ, Lee CU, Lee MS. Executive function in psychiatric patients groups through Wiscondin Card Sorting Test Computer Version (WCST). J Korean Neuropsychiatr Assoc 2002;41:322-334.

42. Pedersen A, Wilmsmeier A, Wiedl KH, Bauer J, Kueppers K, Koelkebeck $\mathrm{K}$, et al. Anterior cingulate cortex activation is related to learning potential on the WCST in schizophrenia patients. Brain Cogn 2012; 79:245-251.

43. Stetina BU, Kothgassner OD, Lehenbauer M, Kryspin-Exner I. Beyond the fascination of online-games: probing addictive behavior and depression in the world of online-gaming. Comput Human Behav 2011; 27:473-479.

44. Loftus GR, Loftus EF. Mind at Play: the Psychology of Video Games. New York: Basic Books; 1983.

45. Taylor TL. Play between Worlds: Exploring Online Game Culture. First Edition. Cambridge, MA: MIT Press; 2006.

46. Griffiths MD, Davies MN, Chappell D. Demographic factors and playing variables in online computer gaming. Cyberpsychol Behav 2004; 7:479-487.

47. Council NR. Pathological Gambling: A Critical Review. Washington DC: National Academy Press; 1999. Available at: http://www.nap.edu/.

48. Li D, Liau A, Khoo A. Examining the influence of actual-ideal self-discrepancies, depression, and escapism, on pathological gaming among massively multiplayer online adolescent gamers. Cyberpsychol Behav Soc Netw 2011;14:535-539.

49. Kuss DJ, Louws J, Wiers RW. Online gaming addiction? Motives predict addictive play behavior in massively multiplayer online role-playing games. Cyberpsychol Behav Soc Netw 2012;15:480-485.

50. Jansz J, Tanis M. Appeal of playing online first person shooter games. Cyberpsychol Behav 2007;10:133-136.

51. Glass BD, Maddox WT, Love BC. Real-time strategy game training: emergence of a cognitive flexibility trait. PLoS One 2013;8:e70350. 